\title{
Atomic layer deposition of zirconium oxide thin films
}

\author{
Xin Wang, Sujan Kumar Ghosh1, Mahyar Afshar-Mohajer ${ }^{1}$, Hua Zhoul', Yongqiang Liu ${ }^{2}$, \\ Xiaoxiao Han", Jiyu. Cail ${ }^{4}$ Min Zou ${ }^{1, a)}$, Xiangbo Meng ${ }^{1, b), c)}$ \\ ${ }^{1}$ Department of Mechanical Engineering, University of Arkansas, Fayetteville, Arkansas 72701, USA; and Center for Advanced Surface Engineering, \\ University of Arkansas, Fayetteville, Arkansas 72701, USA \\ ${ }^{2}$ The Advanced Photon Source, Argonne National Laboratory, Lemont, Illinois 60439, USA \\ ${ }^{3}$ Department of Mechanical Engineering, University of Arkansas, Fayetteville, Arkansas 72701, USA; and Beijing Advanced Innovation Center for \\ Materials Genome Engineering, Center for Green Innovation, Beijing Key Laboratory for Magneto-Photoelectrical Composite and Interface Science, \\ School of Mathematics and Physics, University of Science and Technology Beijing, Beijing 100083, China \\ ${ }^{4}$ Department of Mechanical Engineering, University of Arkansas, Fayetteville, Arkansas 72701, USA \\ a) Address all correspondence to these authors. e-mail: mzou@uark.edu \\ b)e-mail: xbmeng@uark.edu \\ ${ }^{c}$ ) This author was an editor of this journal during the review and decision stage. For the JMR policy on review and publication of manuscripts authored \\ by editors, please refer to http://www.mrs.org/editor-manuscripts/.
}

Received: 12 September 2019; accepted: 9 October 2019

In this work, we studied an atomic layer deposition (ALD) process of $\mathrm{ZrO}_{2}$ with the precursors of tetrakis(dimethylamido)zirconium(IV) and water. We investigated the growth characteristics and mechanism of the ALD $\mathrm{ZrO}_{2}$ in the temperature range of $50-275{ }^{\circ} \mathrm{C}$. Furthermore, the evolutions of film thickness and morphology were studied and discussed. It was found that the growth rate of $\mathrm{ZrO}_{2}$ decreased almost linearly with the increasing temperature from $\sim 1.81 \AA$ 解cle at $50{ }^{\circ} \mathrm{C}$ to $\sim 0.8 \AA /$ cycle at $225^{\circ} \mathrm{C}$. Interestingly, it was revealed that the growth of $\mathrm{ZrO}_{2}$ films ceased after a certain number of ALD cycles at a temperature higher than $250{ }^{\circ} \mathrm{C}$. We also verified that the crystallinity of $\mathrm{ZrO}_{2}$ evolved with deposition temperature from amorphous to crystalline phase. In addition, the wettability of $\mathrm{ZrO}_{2}$ films was studied, showing a hydrophobic nature.

\section{Introduction}

Zirconium oxide $\left(\mathrm{ZrO}_{2}\right)$ is an attractive material in many applications, like ceramics production and optical devices, because of its excellent thermal, mechanical, optical, electrical, and catalytic properties [1, 2, 3, 4]. $\mathrm{ZrO}_{2}$ has three crystalline structures: monoclinic (below $1170{ }^{\circ} \mathrm{C}$ ), tetragonal $\left(1170-2370{ }^{\circ} \mathrm{C}\right.$ ), and cubic (above $2370^{\circ} \mathrm{C}$ ) [2]. The monoclinic phase remains stable at room temperature, and the monoclinic-to-tetragonal and tetragonal-tocubic phase transitions may occur at about $1200{ }^{\circ} \mathrm{C}$ and $2375{ }^{\circ} \mathrm{C}$, respectively [5]. The density of $\mathrm{ZrO}_{2}$ also varies with different crystalline structures, i.e., $5.89,6.16$, and $6.27 \mathrm{~g} / \mathrm{cm}^{3}$ for monoclinic, tetragonal, and cubic phases, respectively [3].

To date, $\mathrm{ZrO}_{2}$ thin films have already been prepared by conventional physical vapor deposition (PVD) and chemical vapor deposition (CVD). A PVD process, such as laser pulse ablation [6] and sputtering [7], enables to control planar film growth. However, they are unable to produce conformal films and also cannot precisely control the thickness of the deposited films. A CVD process typically needs high temperature $\left(>800{ }^{\circ} \mathrm{C}\right)$ and can generate uniform and high-quality films.
However, CVD is also not skilled at producing conformal films. Previously, $\mathrm{ZrO}_{2}$ films have been synthesized via CVD processes using various precursors, such as chloride precursor [8], alkoxide precursors [9], and $\beta$-diketonate precursors [10, 11, 12]. Compared with PVD and CVD processes, atomic layer deposition (ALD) is an alternative technique enabling excellent uniform and conformal films over any shaped substrates at low temperatures, featuring its film controllability at the atomic level [13, 14, 15]. Owing to the many applications of $\mathrm{ZrO}_{2}$, it has been developed via some $\mathrm{ALD}$ processes. There were $\mathrm{Zr}\left[\mathrm{OC}\left(\mathrm{CH}_{3}\right)_{3}\right]_{4}$ [16], $\mathrm{ZrI}_{4}$ [17], and $\mathrm{ZrCl}_{4}[18,19]$ studied as $\mathrm{Zr}$ precursors. In these studies, $\mathrm{H}_{2} \mathrm{O}$ was widely used as the oxygen precursor. Precursors take a critical role in determining the resultant $\mathrm{ZrO}_{2}$ films such as growth per cycle (GPC), crystallinity, and temperature range for deposition. Each precursor has advantages and disadvantages. For example, $\mathrm{ZrCl}_{4}$ is a typical $\mathrm{Zr}$ precursor and it has a high thermal stability $\left(\sim 500{ }^{\circ} \mathrm{C}\right)[20]$, but it suffers from low volatility and needs high evaporation temperature $\left(165^{\circ} \mathrm{C}\right)$ for ALD processes [21]. In addition, there is $\mathrm{HCl}$ generated as the byproduct during ALD processes using $\mathrm{ZrCl}_{4}$ and $\mathrm{H}_{2} \mathrm{O}$, posing risk of corrosion 
[21] and degradation of the film quality [22]. Among all the $\mathrm{Zr}$ precursors investigated so far, tetrakis(dimethylamido)zirconium(IV) $\left[\mathrm{Zr}\left(\mathrm{NMe}_{2}\right)_{4}\right.$ or TDMA-Zr] has shown some benefits over $\mathrm{ZrCl}_{4}$, including high volatility, good thermal stability, and high reactivity to surface ligands (e.g., $-\mathrm{OH})[23,24,25]$. Liu et al. deposited $\mathrm{ZrO}_{2}$ thin films using TDMA-Zr and $\mathrm{H}_{2} \mathrm{O}$ for depositing $\mathrm{ZrO}_{2}$ films on nitrogen-doped carbon nanotubes (N-CNTs) [26] and graphene nanosheets (GNS) [27]. The processes in both studies are based on the following two half reactions, as proposed by Hausmann [23]:

$$
\begin{aligned}
& \mathrm{HOH}+\mathrm{Zr}\left(\mathrm{NMe}_{2}\right)_{4}(\mathrm{~g}) \rightarrow \mathrm{HO}-\mathrm{Zr}\left(\mathrm{NMe}_{2}\right)_{3}+\mathrm{HNMe}_{2}(\mathrm{~g}), \quad, \quad \\
& \mathrm{\vdash O}-\mathrm{Ze}\left(\mathrm{NMe}_{2}\right)_{3}+3 \mathrm{H} \mathrm{H}_{2} \mathrm{O}(\mathrm{g}) \rightarrow \mathrm{HO}-\mathrm{Zr}-(\mathrm{OH})_{3}+3 \mathrm{HNM}_{\mathrm{E} 2}(\mathrm{~g}),
\end{aligned}
$$

where "F" denotes the substrate surface and "(g)" refers to a gaseous phase. The results showed that uniform and conformal films can be developed at temperature as low as $100{ }^{\circ} \mathrm{C}$, and the GPC and crystallinity of $\mathrm{ZrO}_{2}$ thin film
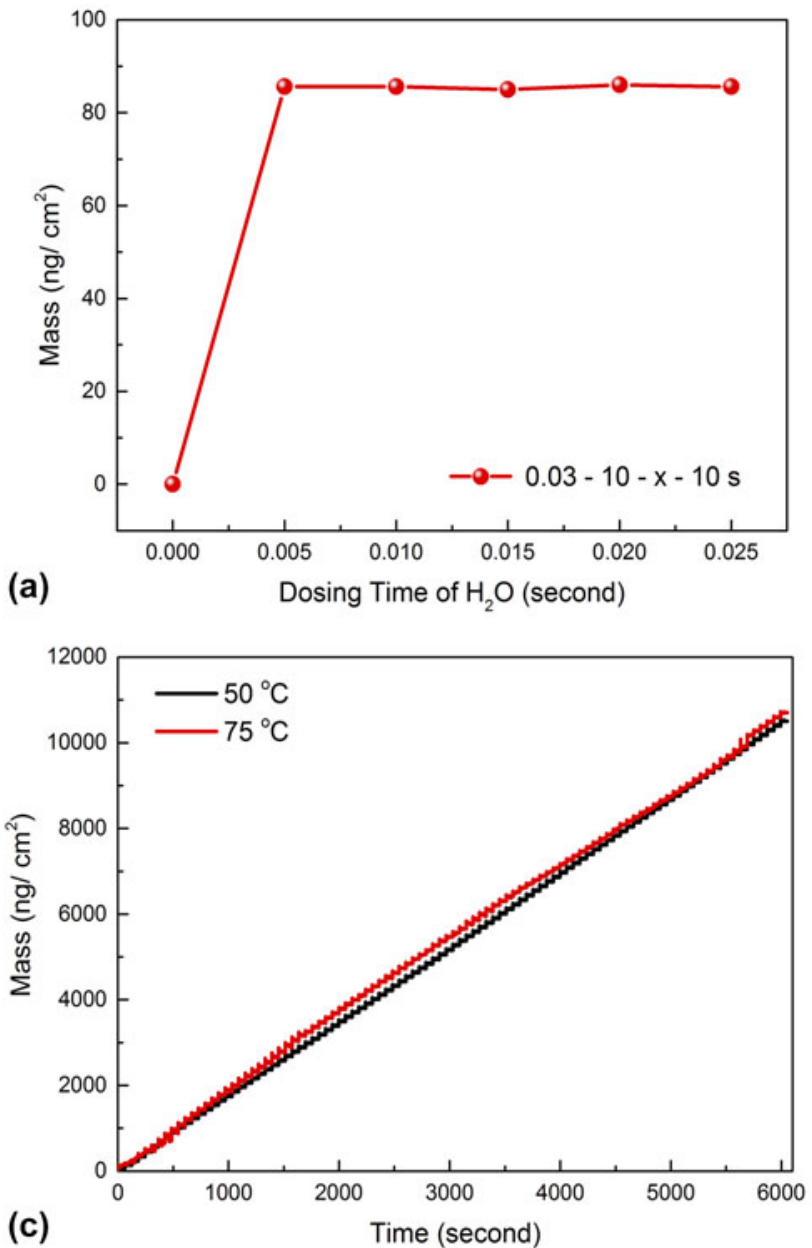

experienced a strong dependence on the deposition temperatures. However, the surface reactions between the precursors were not fully discussed, which are essential for a better understanding of the ALD process of $\mathrm{ZrO}_{2}$.

Stimulated by the tremendous capability for uniform and conformal coatings at low temperature and aimed at further exploring the ALD process using TDMA-Zr and $\mathrm{H}_{2} \mathrm{O}$ as precursors, we recently conducted a systematic study, featuring the utilization of an in situ quartz crystal microbalance (QCM) in a wide temperature range of $50-275{ }^{\circ} \mathrm{C}$. The ALD process was further applied on nitrogen-doped graphene nanosheets (N-GNS) and N-CNTs for investigating film evolution with temperatures and ALD cycles. In addition, the wettability of $\mathrm{ZrO}_{2}$ films was investigated for different film thicknesses and different deposition temperatures.

\section{Results and discussion}

We first conducted a series of studies to optimize ALD dosing and purging parameters at $100^{\circ} \mathrm{C}$, as shown in Figs. 1(a) and
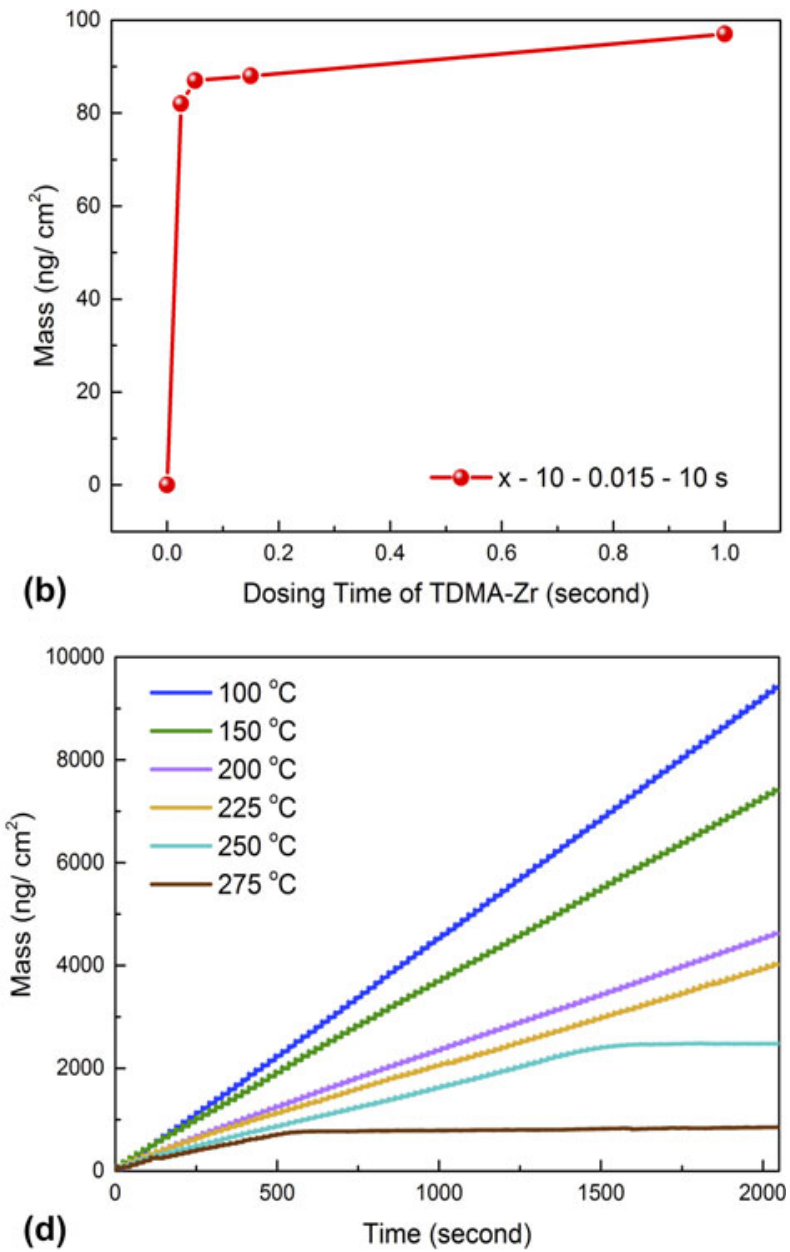

(d)

Figure 1: Optimization of the dosing time of precursors at $100^{\circ} \mathrm{C}$ : (a) the effect of dosing time of $\mathrm{H}_{2} \mathrm{O}$ on the mass gain, (b) the effect of dosing time of TDMA-Z on the mass gain. In situ QCM measurements of $\mathrm{ALD} \mathrm{ZrO}_{2}$ with 100 cycles: (c) using the timing sequence of $0.03-30-0.015-30 \mathrm{~s}$ at 50 and $75{ }^{\circ} \mathrm{C}$, (d) using the timing sequence of $0.03-10-0.015-10 \mathrm{~s}$ in the range of $100-275{ }^{\circ} \mathrm{C}$. 
1(b). With the fixed dosing time of TDMA-Zr (0.03 s) and purging time (10 s), the dosing time of $\mathrm{H}_{2} \mathrm{O}$ was increased from 0 to $0.025 \mathrm{~s}$, and it was observed that the mass gain would maintain the same value as the dosing time of $\mathrm{H}_{2} \mathrm{O}$ reached $0.005 \mathrm{~s}$ or longer [Fig. 1(a)], which indicated the saturation growth of $\mathrm{ZrO}_{2}$; thus, we selected a value of $0.015 \mathrm{~s}$ for the dosing time of $\mathrm{H}_{2} \mathrm{O}$. Similarly, we selected the optimal dosing time of TDMA-Zr as $0.03 \mathrm{~s}$ [Fig. 1(b)]. In addition, in situ QCM measurements were conducted to investigate the growth of $\mathrm{ALD}-\mathrm{ZrO}_{2}$ at various deposition temperatures. Figs. 1(c) and $1(\mathrm{~d})$ illustrate the time-resolved mass changes measured by in situ QCM during 100 ALD cycles using TDMA- $\mathrm{Zr}$ and $\mathrm{H}_{2} \mathrm{O}$ as precursors between 50 and $275^{\circ} \mathrm{C}$. Prior to the $\mathrm{ZrO}_{2} \mathrm{ALD}$, an $\mathrm{ALD} \mathrm{Al}_{2} \mathrm{O}_{3}$ film was deposited on the QCM crystal surface alternately using TMA and $\mathrm{H}_{2} \mathrm{O}$ as precursors with a timing sequence of $0.015-5-0.015-5 \mathrm{~s}$ to establish an uniform starting surface. During the deposition process, the ALD $\mathrm{ZrO}_{2}$ GPC gradually decreased and stabilized to a constant value after the first $\sim 20$ cycles $(0-400 \mathrm{~s})$, and the larger GPC in the first 20 cycles were due to the effect of the predeposited $\mathrm{Al}_{2} \mathrm{O}_{3}$ film. In addition, the mass gain per cycle in the stable regime changes with temperatures, which decreased almost linearly from $100.28 \mathrm{ng} / \mathrm{cm}^{2}$ at $50{ }^{\circ} \mathrm{C}$ to $40.66 \mathrm{ng} / \mathrm{cm}^{2}$ at $225{ }^{\circ} \mathrm{C}$. However, no mass gain can be observed after certain cycles at 250 and $275{ }^{\circ} \mathrm{C}$. This might be related to the precursor decomposition of TDMA-Zr and the exactly underlying reason will be investigated in future studies.

Fig. 2(a) demonstrates the thickness variation of $\mathrm{ZrO}_{2}$ films during $100 \mathrm{ALD}$ cycles from 50 to $275^{\circ} \mathrm{C}$. Supposed that the deposited films are crystalline, having a density of $6.16 \mathrm{~g} / \mathrm{cm}^{3}$, we then could calculate the thickness using the QCM data (ng/ $\mathrm{cm}^{2}$ ). As shown in Fig. 2(a), the thickness of $\mathrm{ZrO}_{2}$ films increases almost as a straight line within 100 cycles at temperatures lower than $225^{\circ} \mathrm{C}$, indicating that at each temperature the GPC is constant. However, the thickness of $\mathrm{ZrO}_{2}$ films at 250 and $275^{\circ} \mathrm{C}$ remains unchanged after 80 and 20 cycles, respectively, which means the growth of the films terminated. It was reported that the maximum ALD temperature of TDMA-Zr is $250{ }^{\circ} \mathrm{C}$ [23]. Therefore, decomposition of TDMA-Zr might be responsible to the growth cessation at the high temperatures of 250 and $275^{\circ} \mathrm{C}$. The GPC of ALD- $\mathrm{ZrO}_{2}$ changes with temperature, as shown in Fig. 2(b). The GPC is calculated to be $1.81,1.84,1.60,1.21,0.67$, and $0.66 \AA$ cycle at the deposition temperatures of $50,75,100,150,200$, and $225^{\circ} \mathrm{C}$, respectively. At low temperatures (i.e., 50 and $75^{\circ} \mathrm{C}$ ), the GPCs are comparable and then significantly decreases with the increasing temperatures. The underlying reasons will be discussed later.

Fig. 3 shows an enlarged view of consecutive $\mathrm{ZrO}_{2}$ ALD cycles in the stable growth regime. Inspired by our previous ALD studies [28, 29, 30], the two half reactions can be rewritten as follow:

$$
\begin{aligned}
& \left\|(\mathrm{OH})_{x}+\mathrm{Zr}\left(\mathrm{NMe}_{2}\right)_{4}(\mathrm{~g}) \rightarrow\right\|_{\mathrm{O}_{x}-\mathrm{Zr}\left(\mathrm{NMe}_{2}\right)_{(4-x)}} \\
& \quad+x \mathrm{H}\left(\mathrm{NMe}_{2}\right)(\mathrm{g}) \\
& \|_{\mathrm{O}_{x}-\mathrm{Zr}\left(\mathrm{NMe}_{2}\right)_{(4-x)}+2 \mathrm{H}_{2} \mathrm{O}(\mathrm{g}) \rightarrow \|_{2}-\mathrm{Zr}-(\mathrm{OH})_{x}} \\
& \quad+(4-x) \mathrm{H}\left(\mathrm{NMe}_{2}\right)(\mathrm{g})
\end{aligned}
$$

where $x$ is between 0 and 4 , indicating the number of reactive surface $(-\mathrm{OH})$ groups. In Eq. (2A), TDMA-Zr reacts with $x-$ $\mathrm{OH}$ while liberating $x$ of $\left(-\mathrm{NMe}_{2}\right)$ into gaseous $\mathrm{C}_{2} \mathrm{H}_{7} \mathrm{~N}$, and the surface mass gain can be expressed as $m_{1}=267-45 x$. In Eq. (2B), $\mathrm{H}_{2} \mathrm{O}$ reacts with $(4-x)\left(-\mathrm{NMe}_{2}\right)$ surface ligands which are then replaced by $x-\mathrm{OH}$ groups, and the surface mass gain can be expressed as $m_{2}=45 x-144$. Thus, the total mass gain

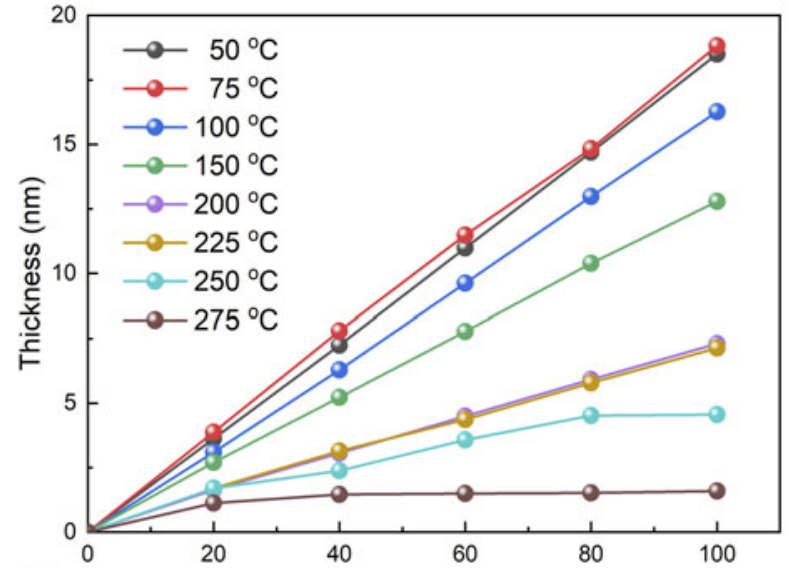

(a)

ALD Cycle Number

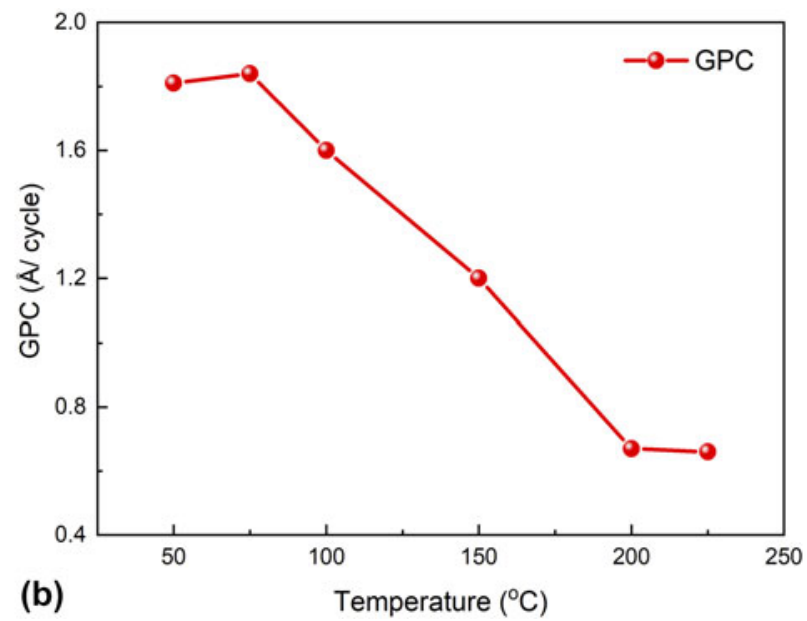

Figure 2: In situ QCM measurements of $\mathrm{ALD} \mathrm{ZrO}_{2}$ at various temperatures using the timing sequence of $0.03-30-0.015-30 \mathrm{~s}$ at 50 and $75{ }^{\circ} \mathrm{C}$, and $0.03-10-0.015-$ $10 \mathrm{~s}$ in the range of $100-275^{\circ} \mathrm{C}$ : (a) The thicknesses of $\mathrm{ZrO}_{2}$ film versus ALD cycle number during $100 \mathrm{ALD}$ cycles and (b) the $\mathrm{GPCs}$ of $\mathrm{ZrO}_{2}$ films versus temperature. 

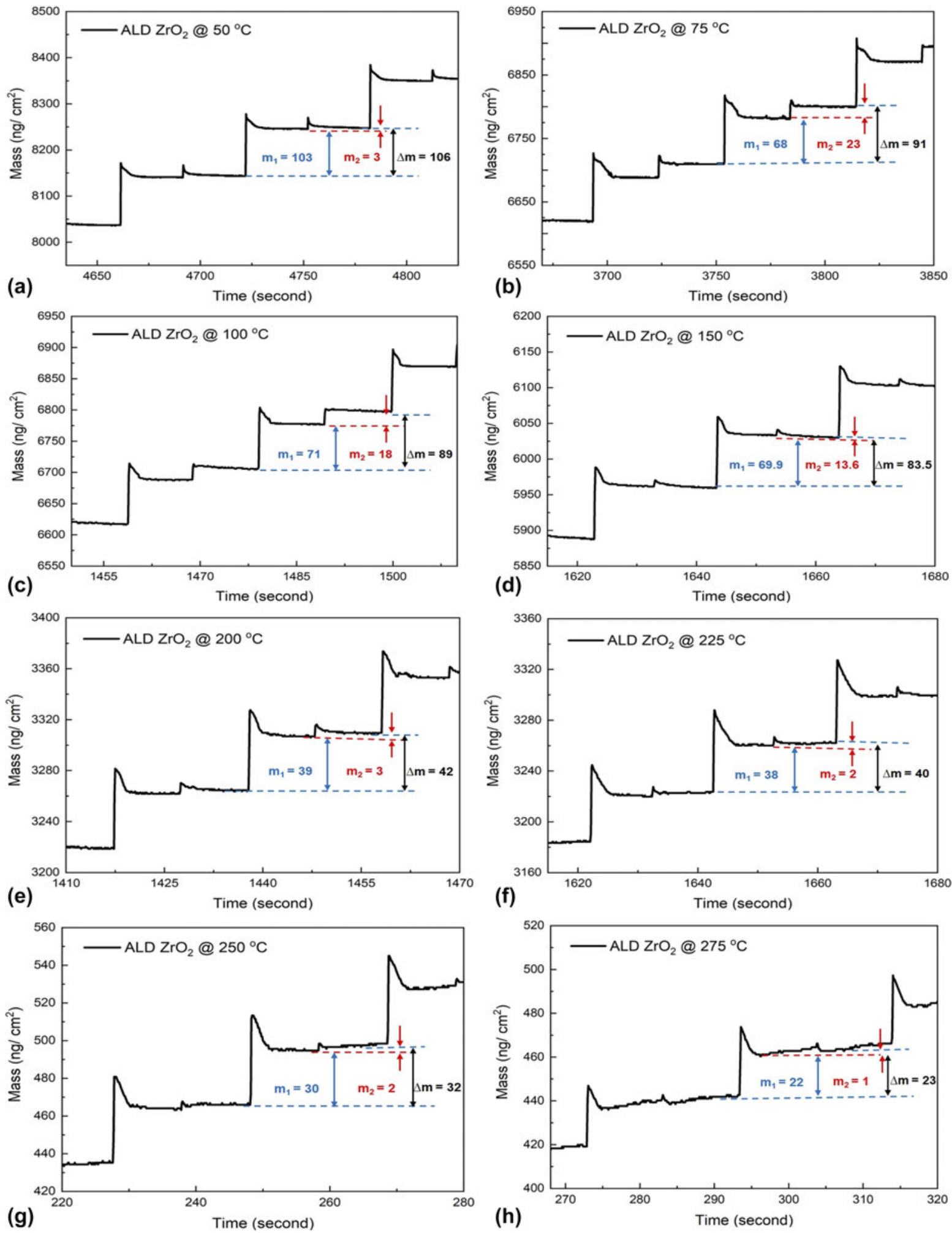

Figure 3: Enlarged view of consecutive ALD cycles of $\mathrm{ZrO}_{2}$ deposition in the regime of steady-state growth at (a) 50, (b) 75, (c) 100, (d) 150, (e) 200, (f) 225, (g) 250 , and (h) $275{ }^{\circ} \mathrm{C}\left(m_{1}, m_{2}\right.$, and $\Delta m$ are illustrated in the text).

for one $\mathrm{ZrO}_{2} \mathrm{ALD}$ cycle is the sum of the mass gain in the two equations, i.e., $\Delta m=m_{1}+m_{2}=123$, which is exactly the molar mass of $\mathrm{ZrO}_{2}$. These equations assume that the $-\mathrm{OH}$ groups are the reactive species for the chemisorption of $\mathrm{Zr}$ precursor. Considering the mass gain $m_{1}$ in Eq. (2A) and the total mass gain $\Delta m$, we can combine them in Eq. (3): 


$$
R=\Delta m / m_{1}=123 /(267-45 x)
$$

where the ratio $R$ reveals the number $x$ of surface $(-\mathrm{OH})$ groups reacting with each TDMA-Zr molecule. For instance, at $75{ }^{\circ} \mathrm{C}, R=1.34$, so that $x=3.9$, implying that $3.9 / 4.0$ (or $\sim 97.5 \%)$ of the $\left(-\mathrm{NMe}_{2}\right)$ ligands are released as gaseous $\mathrm{C}_{2} \mathrm{H}_{7} \mathrm{~N}$, leaving only $\sim 2.5 \%$ on $\mathrm{ZrO}_{x}$ surface following TDMA-Zr reaction [Eq. (2A)]. The $R$ and $x$ values decrease with increasing temperatures from 75 to $275^{\circ} \mathrm{C}$, which means that a greater fraction of the $\left(-\mathrm{NMe}_{2}\right)$ ligands from the same TDMA-Zr were chemisorbed on the surface or, conversely, that the coverage of the surface $(-\mathrm{OH})$ groups was lower at the higher temperatures, either due to the desorption of TDMA-Zr or the dehydration of $-\mathrm{OH}$ sites. The variation of $x$ with deposition temperature is illustrated in Fig. 3. It can be seen that $R$ and $x$ values of $\mathrm{ALD} \mathrm{ZrO}_{2}$ at $50{ }^{\circ} \mathrm{C}$ are lower than that at $75{ }^{\circ} \mathrm{C}$ (Fig. 4). The abnormal behavior may originate from the low value of $m_{2}$, i.e., the low mass gain after $\mathrm{H}_{2} \mathrm{O}$ dosing, as shown in Fig. 3(a), which may be due to the low reactivity of $\mathrm{H}_{2} \mathrm{O}$ or the physical absorption of $\mathrm{H}_{2} \mathrm{O}$ on many reactive sites at $50{ }^{\circ} \mathrm{C}$, resulting in a lower GPC than that of $75^{\circ} \mathrm{C}$.

To verify the GPC of $\mathrm{ZrO}_{2}$ at different temperatures, $\mathrm{ZrO}_{2}$ films were deposited on N-GNS at 75,150 , and $250{ }^{\circ} \mathrm{C}$ with various numbers of ALD cycles, and the $\mathrm{ZrO}_{2}-\mathrm{N}-\mathrm{GNS}$ composites were characterized by scanning electron microscopy (SEM) (Fig. 5). Low-magnification SEM images were inset in Figs. 5(a)-5(i), which indicated that $\mathrm{ZrO}_{2}$ thin films were uniformly deposited onto the N-GNS. At $75{ }^{\circ} \mathrm{C}$, the graphene wrinkles were coated by $\mathrm{ZrO}_{2}$ with 100, 200, and 300 ALD cycles [see Figs. 5(a)-5(c)]. It can be seen that the $\mathrm{ZrO}_{2}$ coatings are very conformal. After 100 ALD cycles, the thickness of the coated N-GNS is measured to be $40 \pm$ $0.5 \mathrm{~nm}$. With the increasing ALD cycles, the coatings become thicker, i.e., the thickness rises to $77 \pm 0.5 \mathrm{~nm}, 115 \pm 0.5 \mathrm{~nm}$

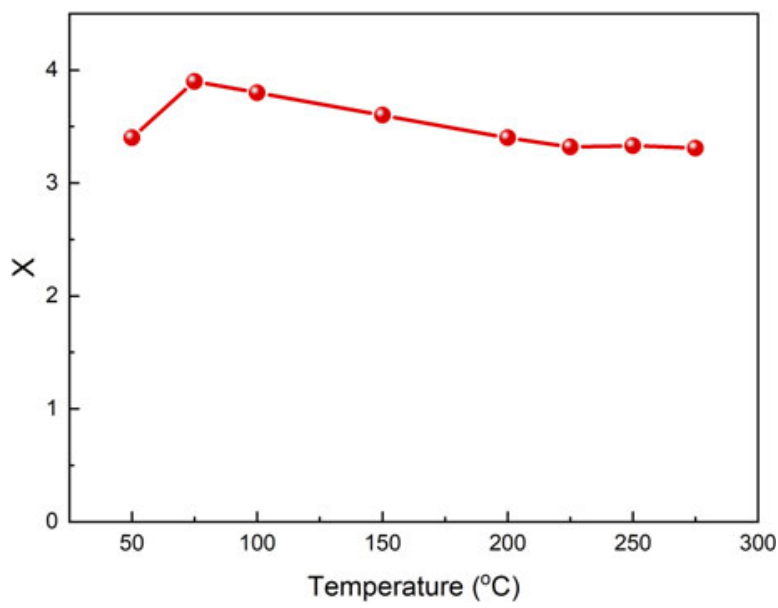

Figure 4: The number $x(0 \leq x \leq 4)$ of surface $(-\mathrm{OH})$ groups reacting with TDMA-Zr at different temperatures. after 200 and 300 cycles, respectively. Furthermore, in our previous study [30], the pristine N-GNS was measured to be $\sim 3 \mathrm{~nm}$ in thickness; therefore, the GPCs of the ALD- $\mathrm{ZrO}_{2}$ were calculated as $1.9 \AA /$ cycle at $75^{\circ} \mathrm{C}$, which is a little bit higher but very close to that of QCM data. The calculation is based on the following equation: GPC $=$ (wrinkle thickness of coated N-GNS-wrinkle thickness of pristine N-NGS)/(2 $\times$ cycle numbers) [31]. The growth of ALD- $\mathrm{ZrO}_{2}$ on $\mathrm{N}-\mathrm{GNS}$ with different cycles at $150{ }^{\circ} \mathrm{C}$ exhibits the similar trend as that at $75^{\circ} \mathrm{C}$, as shown in Figs. $5(\mathrm{~d})-5(\mathrm{f})$, and the GPC is calculated as $\sim 1.3 \AA$ /cycle. To confirm the terminating growth of ALD$\mathrm{ZrO}_{2}$ after 80 cycles at $250{ }^{\circ} \mathrm{C}$, the coating was also performed for 25, 75, and 100 cycles, as shown in Figs. 5(g)-5(i). From the thickness variation of coated N-GNS with 25 and 75 cycles, the GPC is estimated as $\sim 0.5 \AA /$ cycle. Compared with that of 75 cycles, however, the coated N-GNS of 100 cycles almost maintains the same thickness. This corroborates the QCM data, indicating that the growth of ALD- $\mathrm{ZrO}_{2}$ indeed terminated after 80 cycles at $250{ }^{\circ} \mathrm{C}$.

Atomic force microscope (AFM) images of $\mathrm{ZrO}_{2}$ coating on glass substrate are shown in Fig. 6. According to the QCM results, the GPCs are $\sim 1.8,1.2$, and $0.7 \AA$ /cycle at 50, 150, and $225^{\circ} \mathrm{C}$, respectively. To facilitate the comparison of films with a similar thickness, we deposited $\mathrm{ZrO}_{2}$ films for 10 cycles at $50{ }^{\circ} \mathrm{C}, 15$ cycles at $150{ }^{\circ} \mathrm{C}$, and 25 cycles at $225^{\circ} \mathrm{C}$, having a similar thickness of $\sim 1.8 \mathrm{~nm}$. We also deposited films for 300 cycles at $50{ }^{\circ} \mathrm{C}, 400$ cycles at $150{ }^{\circ} \mathrm{C}$, and 700 cycles at $225^{\circ} \mathrm{C}$, having a comparable thickness of $\sim 50 \mathrm{~nm}$. It was observed that deposition temperature and film thickness have some remarkable effects on the film topography. At each temperature, high ALD cycles (e.g., $\sim 50$ nm-thick films) resulted in more uniform films. In the cases of $\sim 1.8 \mathrm{~nm}$-thick films, the 10 cycle film at $50{ }^{\circ} \mathrm{C}$ might not have fully covered the substrate. Interestingly, the 15 -cycle film deposited at $150{ }^{\circ} \mathrm{C}$ showed many nanorod-like structures, while the 25 -cycle film deposited at $250{ }^{\circ} \mathrm{C}$ showed a more uniform structure. The nanorod-like structure might be related to phase transition, i.e., the existence of sparse nanoparticles before the full formation of nanofilms, which can be observed in others' ALD studies $[26,27,31,32,33]$. One can also find that at each temperature, the thicker coating generally has a higher roughness than the thin one.

We further clarified the crystallinity of $\mathrm{ZrO}_{2}$ films with deposition temperature using synchrotron-based X-ray diffraction (XRD). $\mathrm{ZrO}_{2}$ films were deposited on N-CNTs for 100 ALD cycle at $75,100,150,200$, and $250{ }^{\circ} \mathrm{C}$. The XRD patterns of the pristine $\mathrm{N}-\mathrm{CNT}$ and the resultant $\mathrm{ZrO}_{2}-\mathrm{N}-\mathrm{CNT}$ composites are shown in Fig. 7. It can be seen that all samples at these temperatures exhibit three peaks at $30^{\circ}, 50^{\circ}$, and $62^{\circ}$, which are indexed as (002), (100), and (004) planes of graphite, respectively (JCPDS PDF No. 08-0415). For the $\mathrm{ZrO}_{2}$-CNTs 

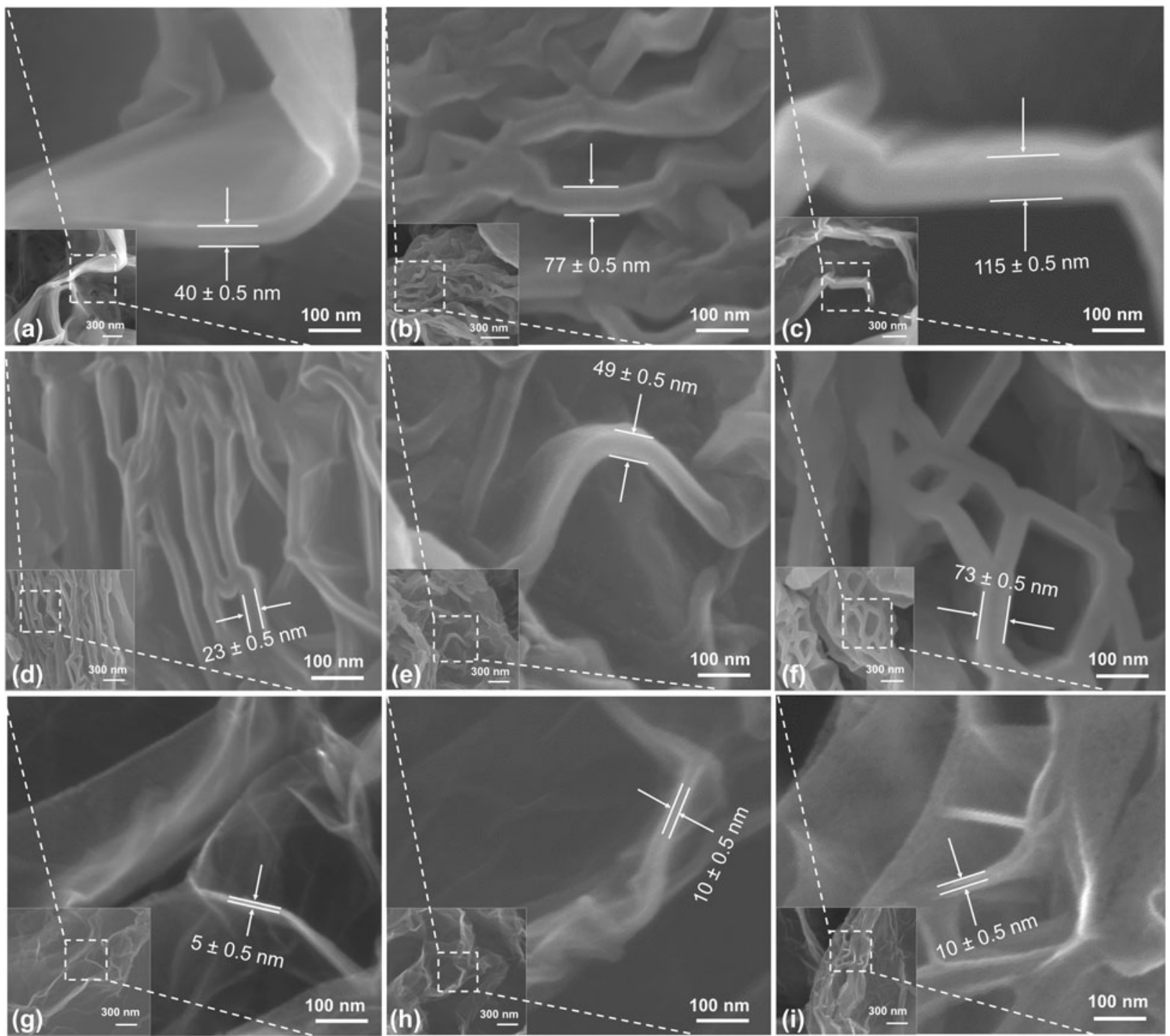

Figure 5: SEM images of $\mathrm{ZrO}_{2}-\mathrm{N}-\mathrm{GNS}$ composites prepared at $(\mathrm{a}, \mathrm{b}, \mathrm{c}) 75^{\circ} \mathrm{C}(\mathrm{d}, \mathrm{e}, \mathrm{f}) 150^{\circ} \mathrm{C}$, and $(\mathrm{g}, \mathrm{h}, \mathrm{i}) 250^{\circ} \mathrm{C}$ with $(\mathrm{a}, \mathrm{d}) 100 \mathrm{ALD}$ cycles $(\mathrm{b}, \mathrm{e}) 200 \mathrm{ALD}$ cycles, (c, f) 300 ALD cycles, (g) 25 ALD cycles, (h) 75 ALD cycles, and (i) 100 ALD cycles.

prepared at $150,200,250{ }^{\circ} \mathrm{C}$, the peaks located at $36^{\circ}$ correspond well to the plane (101) of tetragonal $\mathrm{ZrO}_{2}$ (JCPDS PDF No. 50-1089). This is consistent to Liu's work [26]. Because the deposited $\mathrm{ZrO}_{2}$ films were pretty thin, other XRD peaks of $\mathrm{ZrO}_{2}$ are not identifiable. At low deposition temperatures of 75 and $100{ }^{\circ} \mathrm{C}$, the (101) peak becomes much broader. This implies the amorphous structure of $\mathrm{ZrO}_{2}$.

The tetragonal $\mathrm{ZrO}_{2}$ typically exists at high temperature $\left(1170-2370{ }^{\circ} \mathrm{C}\right)$ [2], whereas in our study, this phase was not only prepared between 150 and $250^{\circ} \mathrm{C}$ but also was stable at room temperature. The existence of tetragonal $\mathrm{ZrO}_{2}$ at low temperatures was found in previous reports $[34,35,36$, 37]. As pointed out in previous studies, this phenomenon may be related to the grain size. Small $\mathrm{ZrO}_{2}$ size and high specific surface area might have provided sufficient surface energy to stabilize the metastable tetragonal phase at low temperatures.

Furthermore, we investigated water contact angles of $\mathrm{ZrO}_{2}$ films, as shown in Fig. 8. As we can see, all the water contact angles of the samples are larger than $90^{\circ}$ regardless of the thickness and deposition temperatures, indicating that the $\mathrm{ZrO}_{2}$ thin films are hydrophobic. For the same thickness of $\mathrm{ZrO}_{2}$ thin films, the water contact angles decreased with the increasing temperatures. In other words, the $\mathrm{ZrO}_{2}$ thin films are more hydrophobic at lower temperatures. At each temperature, the thicker films would result in larger water contact angles, that is, the thicker films are more hydrophobic than the thinner ones at 50,150 , and $225^{\circ} \mathrm{C}$. The surface wettability is related to surface microstructures and surface functional groups [38, 39]. 

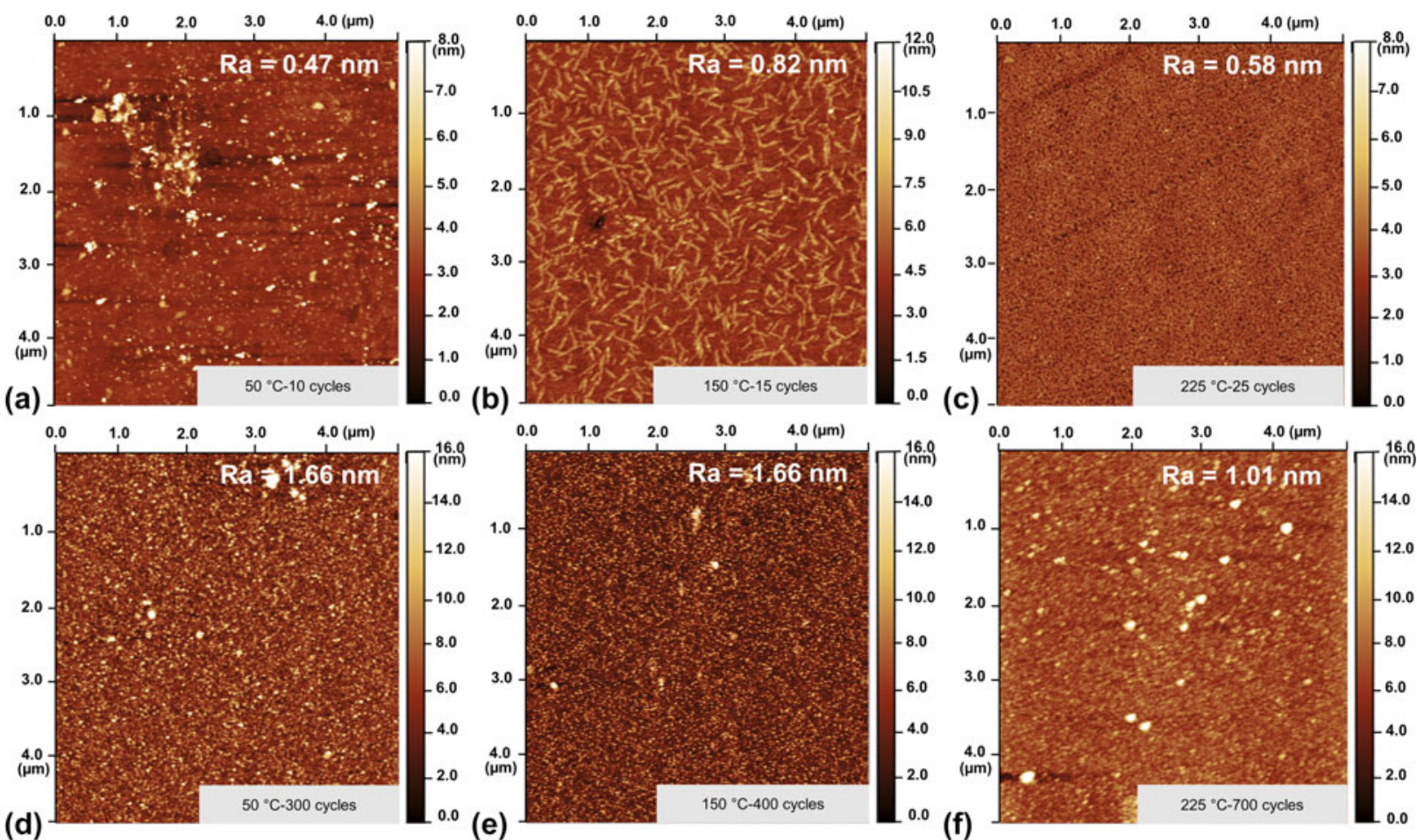

Figure 6: AFM images of $\mathrm{ALD} \mathrm{ZrO}_{2}$ films deposited on glass substrates with (a) 10 cycles at $50{ }^{\circ} \mathrm{C}$, (b) $15 \mathrm{cycles}$ at $150{ }^{\circ} \mathrm{C}$, and (c) $25 \mathrm{cycles}$ at $225^{\circ} \mathrm{C}$, (d) 300 cycles at $50{ }^{\circ} \mathrm{C}$, (e) 400 cycles at $150{ }^{\circ} \mathrm{C}$, and (f) 700 cycles at $225^{\circ} \mathrm{C}$. The average roughness is also presented in each figure. The scanned area is $5 \times 5 \mu \mathrm{m}$.

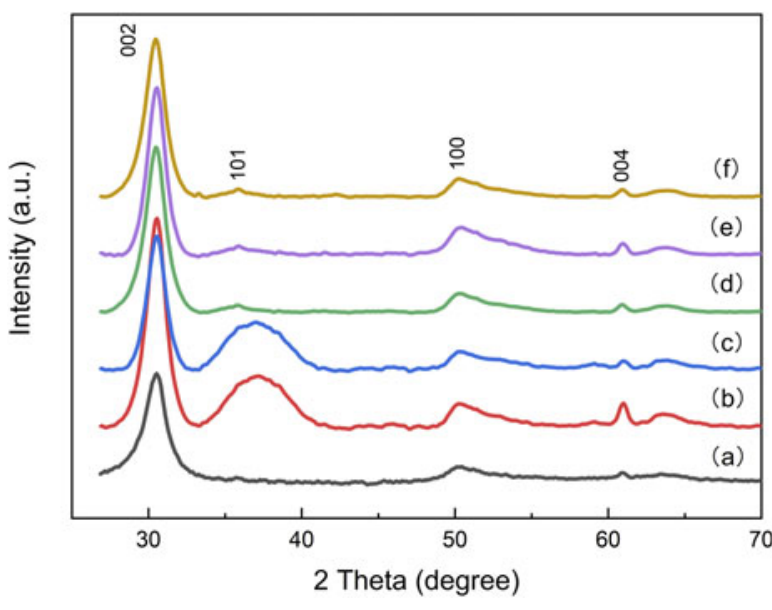

Figure 7: XRD patterns of (a) the pristine $\mathrm{N}-\mathrm{CNTS}$, and $\mathrm{ZrO}_{2}$-coated N-CNTs with 100 ALD cycles prepared at (b) 75 , (c) 100 , (d) 150 , (e) 200 , and (f) $250^{\circ} \mathrm{C}$.

\section{Conclusions}

In this work, we systematically studied the growth characteristics of ALD $\mathrm{ZrO}_{2}$ using TDMA-Zr and $\mathrm{H}_{2} \mathrm{O}$ as precursors. The study confirmed that there has a phase evolution for ALD $\mathrm{ZrO}_{2}$ films with temperature, changing from an amorphous phase at temperatures lower than $100{ }^{\circ} \mathrm{C}$ to a crystalline phase at temperatures higher than $150{ }^{\circ} \mathrm{C}$. At the same time, it was

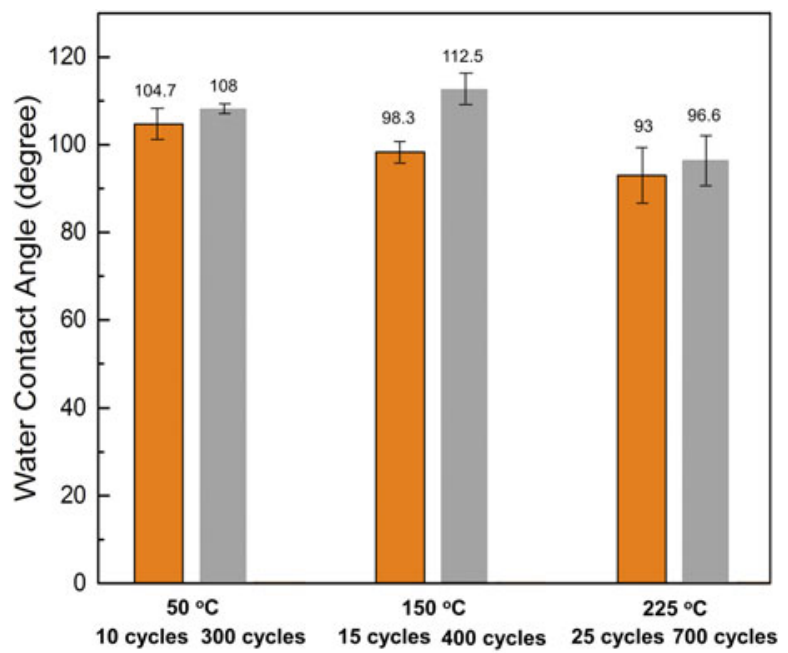

Sample Type

Figure 8: Water contact angles of $\mathrm{ZrO}_{2}$ films deposited with various ALD cycles at different temperatures.

found that the GPCs of ALD $\mathrm{ZrO}_{2}$ films are dependent to deposition temperatures. The GPC could be precisely controlled at the atomic level for various growth temperatures, changing from $\sim 1.8$ at $50{ }^{\circ} \mathrm{C}$ to $0.7 \AA /$ cycle at $225{ }^{\circ} \mathrm{C}$. Furthermore, it was found that the deposited $\mathrm{ZrO}_{2}$ films showed a hydrophobic nature. 


\section{Experimental section}

\section{QCM of $\mathrm{ZrO}_{2}$}

In situ QCM can be used to track the mass variation of deposited $\mathrm{ZrO}_{2}$ films. The measurements were conducted at 50, 75, 100, $150,200,225,250$, and $275{ }^{\circ} \mathrm{C}$ using TDMA-Zr and $\mathrm{H}_{2} \mathrm{O}$ as precursors in an ALD reactor (Savannah 200, Cambridge Nanotech Inc., Cambridge, MA). $6 \mathrm{MHz}$ quartz crystals (\#750-1059G10, Inficon, East Syracuse, NY) were used. Prior to the QCM measurements at each deposition temperature, 50-cycle ALD of $\mathrm{Al}_{2} \mathrm{O}_{3}$ was performed using trimethylaluminum $\left(\mathrm{Al}\left(\mathrm{CH}_{3}\right)_{3}\right.$ or TMA) and $\mathrm{H}_{2} \mathrm{O}$ as precursors to maintain a consistent starting surface. Prior to ALD deposition, TDMA-Zr was heated to $75^{\circ} \mathrm{C}$ for supplying sufficient precursor vapor, whereas $\mathrm{H}_{2} \mathrm{O}$ was kept at room temperature. The delivery pipelines and valve manifold were kept at $90{ }^{\circ} \mathrm{C}$ to prevent the condensation of $\mathrm{Zr}$ precursor, and the exhaust pipelines was heated to $150{ }^{\circ} \mathrm{C}$ for removing any excessive precursor vapors and other by-products. High purity Argon (Ar) gas was used as the carrier gas with a flow rate of $20 \mathrm{sccm}$, and the ALD reactor was kept at a low-level base pressure of 0.3-0.4 torr by a vacuum pump (Pascal 2021C2, Adixen, Jefferson Hills, PA). One ALD cycle was performed with four steps in the temperature range of $100-275{ }^{\circ} \mathrm{C}$ : (i) a 0.03 -s dose of $\mathrm{Zr}\left(\mathrm{NMe}_{2}\right)_{4}$, (ii) a 10-s purge of $\mathrm{Ar}$ gas to remove excessive $\mathrm{Zr}\left(\mathrm{NMe}_{2}\right)_{4}$ and by-products, (iii) a $0.015 \mathrm{~s}$ dose of $\mathrm{H}_{2} \mathrm{O}$, and (iv) a 10-s purge of Ar gas to remove excessive $\mathrm{H}_{2} \mathrm{O}$ and by-products. At low temperatures of 50 and $75{ }^{\circ} \mathrm{C}$, the purging time was increased to $30 \mathrm{~s}$ to fully purge the ALD system while the dosing times were kept as the same.

\section{Preparation and characterization of $\mathrm{ZrO}_{2}$ films}

$\mathrm{ZrO}_{2}$ films were deposited on N-CNTs, N-GNS, and glass substrates for characterization. Synchrotron-based XRD was performed to characterize the crystallinity of the $\mathrm{ZrO}_{2}-\mathrm{N}-\mathrm{CNTs}$ composites, prepared at $75,100,150,200$, and $250{ }^{\circ} \mathrm{C}$. The XRD measurements were conducted using an X-ray wavelength of $0.4336 \AA$ at the beamline 13 BM-C of the Advanced Photon Source (APS) at Argonne National Laboratory (ANL; Illinois). Scanning electron microscopy (SEM) (XL30, Philips FEI, Hillsboro, $\mathrm{OR}$ ) was used to characterize the thickness changes of $\mathrm{ZrO}_{2}$-coated $\mathrm{N}$-GNS with various ALD cycles at different temperatures. AFM (Dimension Icon, Bruker Nano Surfaces, Billerica, MA) was used to measure the roughness of the thin films. Water contact angle test was employed to determine the wettability of $\mathrm{ZrO}_{2}$ films on glass substrates via Contact Angle Measuring System (OCA 15, DataPhysics Instruments $\mathrm{GmbH}$, Filderstadt, Germany).

\section{Acknowledgment}

Funding for this research was provided by the Center for Advanced Surface Engineering, under the National Science
Foundation Grant No. OIA-1457888 and the Arkansas EPSCoR Program, ASSET III. Portions of this work were performed at GeoSoilEnviroCARS (the University of Chicago, Sector 13), APS, Argonne National Laboratory. GeoSoilEnviroCARS is supported by the National Science Foundation-Earth Sciences (EAR1634415) and Department of Energy-GeoSciences (DE-FG0294ER14466). This research used resources of the APS, a U.S. Department of Energy (DOE) Office of Science User Facility operated for the DOE Office of Science by Argonne National Laboratory under Contract No. DE-AC02-06CH11357. We appreciate the assistance provided by Professor Peter Eng (Research Professor, CARS and JFI, University of Chicago) at the University of Chicago.

\section{References}

1. J. Lu, J.B. Zang, S.X. Shan, H. Huang, and Y.H. Wang: Synthesis and characterization of core-shell structural MWNT-zirconia nanocomposites. Nano Lett. 8, 4070 (2008).

2. T. Luo, T. Liang, and C. Li: Stabilization of cubic zirconia by carbon nanotubes. Mater. Sci. Eng. A 366, 206 (2004).

3. J. Nawrocki, M. Rigney, A. McCormick, and P.W. Carr: Chemistry of zirconia and its use in chromatography. J. Chromatogr. A 657, 229 (1993).

4. K. Asakura, M. Aoki, and Y. Iwasawa: Selective isopentane formation from $\mathrm{CH}_{3} \mathrm{OH}$ on a new one-atomic layer $\mathrm{ZrO}_{2} / \mathrm{ZSM}-5$ hybrid catalyst. Catal. Lett. 1, 395 (1988).

5. I. Molodetsky, A. Navrotsky, M.J. Paskowitz, V.J. Leppert, and S.H. Risbud: Energetics of X-ray-amorphous zirconia and the role of surface energy in its formation. J. Non-Cryst. Solids 262, 106 (2000).

6. G. Reiße, B. Keiper, S. Weißmantel, H. Johansen, R. Scholz, and T. Martini: Properties of laser pulse deposited oxide films. Thin Solid Films 241, 119 (1994).

7. A.K. Jonsson, G.A. Niklasson, and M. Veszelei: Electrical properties of $\mathrm{ZrO}_{2}$ thin films. Thin Solid Films 402, 242 (2002).

8. R.N. Tauber, A.C. Dumbri, and R.E. Caffrey: Preparation and properties of pyrolytic zirconium dioxide films. J. Electrochem. Soc. 118, 747 (1971).

9. T.S. Jeon, J.M. White, and D.L. Kwong: Thermal stability of ultrathin $\mathrm{ZrO}_{2}$ films prepared by chemical vapor deposition on Si(100). Appl. Phys. Lett. 78, 368 (2001).

10. M. Balog, M. Schieber, S. Patai, and M. Michman: Thin films of metal oxides on silicon by chemical vapor deposition with organometallic compounds. J. Cryst. Growth 17, 298 (1972).

11. M. Balog, M. Schieber, M. Michman, and S. Patai: The chemical vapour deposition and characterization of $\mathrm{ZrO}_{2}$ films from organometallic compounds. Thin Solid Films 47, 109 (1977).

12. M. Balog, M. Schieber, M. Michman, and S. Patai: The characteristics of growth of films of zirconium and hafnium oxides $\left(\mathrm{ZrO}_{2}, \mathrm{HfO}_{2}\right)$ by thermal decomposition of zirconium and hafnium 
$\beta$-diketonate complexes in the presence and absence of oxygen. $J$. Electrochem. Soc. 126, 1203 (1979).

13. S.M. George: Atomic layer deposition: An overview. Chem. Rev. 110, 111 (2010).

14. R.L. Puurunen: Surface chemistry of atomic layer deposition: A case study for the trimethylaluminum/water process. J. Appl. Phys. 97, 121301 (2005).

15. X. Meng, X. Yang, and X. Sun: Emerging applications of atomic layer deposition for lithium-ion battery studies. Adv. Mater. 24, 3589 (2012).

16. K. Kukli, M. Ritala, and M. Leskelä: Low-temperature deposition of zirconium oxide-based nanocrystalline films by alternate supply of $\mathrm{Zr}\left[\mathrm{OC}\left(\mathrm{CH}_{3}\right)_{3}\right]_{4}$ and $\mathrm{H}_{2} \mathrm{O}$. Chem. Vap. Deposition 6, 297 (2000).

17. K. Kukli, K. Forsgren, J. Aarik, T. Uustare, A. Aidla,

A. Niskanen, M. Ritala, M. Leskelä, and A. Hårsta: Atomic layer deposition of zirconium oxide from zirconium tetraiodide, water and hydrogen peroxide. J. Cryst. Growth 231, 262 (2001).

18. K. Kukli, M. Kemell, J. Köykkä, K. Mizohata, M. Vehkamäki, M. Ritala, and M. Leskelä: Atomic layer deposition of zirconium dioxide from zirconium tetrachloride and ozone. Thin Solid Films 589, 597 (2015).

19. A. Tamm, J. Kozlova, T. Arroval, L. Aarik, P. Ritslaid,

H. García, H. Castán, S. Dueñas, K. Kukli, and J. Aarik: Atomic layer deposition and characterization of dysprosium-doped zirconium oxide thin films. Chem. Vap. Deposition 21, 181 (2015).

20. M. Cassir, F. Goubin, C. Bernay, P. Vernoux, and D. Lincot: Synthesis of $\mathrm{ZrO}_{2}$ thin films by atomic layer deposition: Growth kinetics, structural and electrical properties. Appl. Surf. Sci. 193, 120 (2002).

21. W.H. Nam and S.W. Rhee: Atomic layer deposition of $\mathrm{ZrO}_{2}$ thin films using dichlorobis[bis-(trimethylsilyl)amido]zirconium and water. Chem. Vap. Deposition 10, 201 (2004).

22. J.K. An, J.T. Kim, G. Kang, N.K. Oh, S.H. Hahm, G. Lee, I.S. Park, and J.Y. Yun: $\mathrm{ZrO}_{2}$ film prepared by atomic layer deposition using less viscous cocktail $\mathrm{CpZr}\left[\mathrm{N}\left(\mathrm{CH}_{3}\right)_{2}\right]_{3} / \mathrm{C}_{7} \mathrm{H}_{8}$ precursor and ozone. J. Alloys Compd. 701, 310 (2017).

23. D.M. Hausmann, E. Kim, J. Becker, and R.G. Gordon: Atomic layer deposition of hafnium and zirconium oxides using metal amide precursors. Chem. Mater. 14, 4350 (2002).

24. D.M. Hausmann and R.G. Gordon: Surface morphology and crystallinity control in the atomic layer deposition (ALD) of hafnium and zirconium oxide thin films. J. Cryst. Growth 249, 251 (2003).

25. J.S. Becker, E. Kim, and R.G. Gordon: Atomic layer deposition of insulating hafnium and zirconium nitrides. Chem. Mater. 16, 3497 (2004).

26. J. Liu, X. Meng, M.N. Banis, M. Cai, R. Li, and X. Sun: Crystallinity-controlled synthesis of zirconium oxide thin films on nitrogen-doped carbon nanotubes by atomic layer deposition. J. Phys. Chem. C 116, 14656 (2012).
27. J. Liu, X. Meng, Y. Hu, D. Geng, M.N. Banis, M. Cai, R. Li, and X. Sun: Controlled synthesis of zirconium oxide on graphene nanosheets by atomic layer deposition and its growth mechanism. Carbon 52, 74 (2013).

28. X. Meng, J.A. Libera, T.T. Fister, H. Zhou, J.K. Hedlund, P. Fenter, and J.W. Elam: Atomic layer deposition of gallium sulfide films using hexakis(dimethylamido)digallium and hydrogen sulfide. Chem. Mater. 26, 1029 (2014).

29. X. Meng, Y. Cao, J.A. Libera, and J.W. Elam: Atomic layer deposition of aluminum sulfide: Growth mechanism and electrochemical evaluation in lithium-ion batteries. Chem. Mater. 29, 9043 (2017).

30. J. Cai, Z. Ma, U. Wejinya, M. Zou, Y. Liu, H. Zhou, and X. Meng: A revisit to atomic layer deposition of zinc oxide using diethylzinc and water as precursors. J. Mater. Sci. 54, 5236 (2019).

31. X. Meng, D. Geng, J. Liu, R. Li, and X. Sun: Controllable synthesis of graphene-based titanium dioxide nanocomposites by atomic layer deposition. Nanotechnology 22, 165602 (2011).

32. X. Meng, Y. Zhang, S. Sun, R. Li, and X. Sun: Three growth modes and mechanisms for highly structure-tunable $\mathrm{SnO}_{2}$ nanotube arrays of template-directed atomic layer deposition. $J$. Mater. Chem. 21, 12321 (2011).

33. X. Meng, Y. Zhong, Y. Sun, M. Norouzi Banis, R. Li, and X. Sun: Nitrogen-doped carbon nanotubes coated by atomic layer deposited $\mathrm{SnO}_{2}$ with controlled morphology and phase. Carbon 49 , 1133 (2011).

34. R.C. Garvie: The occurrence of metastable tetragonal zirconia as a crystallite size effect. J. Phys. Chem. 69, 1238 (1965).

35. S. Ferrari, D.T. Dekadjevi, S. Spiga, G. Tallarida, C. Wiemer, and M. Fanciulli: Structural and electrical characterization of ALCVD $\mathrm{ZrO}_{2}$ thin films on silicon. J. Non-Cryst. Solids 303, 29 (2002).

36. M.W. Pitcher, S.V. Ushakov, A. Navrotsky, B.F. Woodfield, G. Li, J. Boerio-Goates, and B.M. Tissue: Energy crossovers in nanocrystalline zirconia. J. Am. Ceram. Soc. 88, 160 (2005).

37. L. Chen, T. Mashimo, E. Omurzak, H. Okudera, C. Iwamoto, and A. Yoshiasa: Pure tetragonal $\mathrm{ZrO}_{2}$ nanoparticles synthesized by pulsed plasma in liquid. J. Phys. Chem. C 115, 9370 (2011).

38. G.K. Hyde, G. Scarel, J.C. Spagnola, Q. Peng, K. Lee, B. Gong, K.G. Roberts, K.M. Roth, C.A. Hanson, C.K. Devine, S.M. Stewart, D. Hojo, J.S. Na, J.S. Jur, and G.N. Parsons: Atomic layer deposition and abrupt wetting transitions on nonwoven polypropylene and woven cotton fabrics. Langmuir $\mathbf{2 6}$, 2550 (2010)

39. K. Lee, J.S. Jur, D.H. Kim, and G.N. Parsons: Mechanisms for hydrophilic/hydrophobic wetting transitions on cellulose cotton fibers coated using $\mathrm{Al}_{2} \mathrm{O}_{3}$ atomic layer deposition. J. Vac. Sci. Technol 30, 01A163 (2012). 